\title{
Risk Factors in Young Stroke
}

\author{
Md. Harun Ur Rashid, ${ }^{1}$ M. A. Kashem, ${ }^{2}$ Sarmistha Biswas, ${ }^{3}$ Mohammad Mahfuzul Hoque ${ }^{4}$
}

\begin{abstract}
:
Background: Stroke in young age is less frequent than in older populations but has a major impact on the individual and society. This study was done to find out aetiological pattern and associated risk factors of stroke in young adults.

Methods: This descriptive cross-sectional observational study was conducted in the Department of Medicine and Neurology, Dhaka Medical College, Dhaka, during the period of April to October 2016. We studied consecutive 100 stroke patients between the age of 15-45 years.

Results: In this study $62 \%$ patients were male and $38 \%$ were female, male incidence is $24 \%$ higher than female and ratio is I. 38. Infarction was found in $65 \%$ cases. Haemorrhage was in $35 \%$ cases. Dyslipidaemia was mostly associated risk factor in both infarction (76. 91\%) and in haemorrhage (85. 71\%). High prevalence of dyslipidaemia as associated risk factor may indicate premature atherosclerosis.

Conclusion: Stroke in young requires a different approach to investigation and management than stroke in the elderly due to differences in the relative frequencies of possible underlying causes. It remains the case, however, that atherosclerosis contributes to a large proportion of stroke in young patients, thus conventional risk factors must be targeted aggressively.
\end{abstract}

Keywords: Risk Factor, young stroke, haemorrhagic stroke, infarctive stroke.

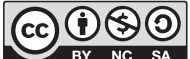

DOI: https://doi.org/l0.3329/jom.v2lil.44097

Copyright: (C) 2020 Rashid MHU et al. This is an open access article published under the Creative Commons Attribution-NonCommercial-NoDerivatives 4.0 International License, which permits use, distribution and reproduction in any medium, provided the original work is properly cited, is not changed in any way and it is not used for commercial purposes.

Received: 30 October, 2018;

Accepted: 07 January, 2019

\section{Introduction:}

Stroke is a major cause of morbidity and mortality. It is one of the most common neurological disorders and third common cause of death worldwide. ${ }^{1}$ The world health organization defined stroke as a syndrome of rapidly developing clinical sign of focal or global disturbance of cerebral function, persisting for at least 24 hours or leading to death with no apparent cause other than vascular origin. ${ }^{1}$ Stroke may be ischemic or hemorrhagic and usually occurs in the elderly and middle aged.

1. Indoor Medical Officer, Dept. of Medicine, Dhaka Medical College \& Hospital.

2. Professor, Dept. of Medicine, Dhaka Medical College \& Hospital.

3. Associate Professor, Dept. of Medicine, Dhaka Medical College \& Hospital.

4. Junior Consultant, Dept. of Medicine, Dhaka Medical College \& Hospital.

Corresponding author: Dr. Md. Harun Ur Rashid, Indoor Medical Officer, Dept. of Medicine, Dhaka Medical College \& Hospital. Cell: 01737220523,E-mail: drharun2100@gmail.com.
The occurrence of stroke in the age group of 15-45 years is referred to as stroke in young adults. ${ }^{1}$ Strokes in this group are relatively uncommon. National survey of stroke in USA revealed that only $3.7 \%$ of all strokes occurred among patient's aged $15-45$ years. Approximately $10 \%$ to $14 \%$ of ischemic strokes occur in young adults. ${ }^{2}$ A hospital based study done in Dhaka Medical College Hospital showed that among all the stroke patients only $1 \%$ suffered stroke is less than 20 years age group and $26 \%$ within $20-45$ years. ${ }^{3}$ Moreover, age specific prevalence of stroke (34-45y) of a population based study done in Bangladesh revealed 4. 37 per 1000 is higher than that of Taiwan, where the prevalence was reported 0.51 per 1000 persons aged 35 to 44 years. This comparison indicates that the stroke prevalence in young Bangladeshi population is much higher than the Asian fareast, commonly known for high prevalence of stroke. ${ }^{3,4}$

The etiology and prognostic features that characterize stroke in older persons may not apply to young adults. Stroke in young adults include a wide variety of disorders those are less frequent in older age groups. Though there are some 
overlap in the risk factors between these two groups but there are some clearly distinct risk factors for ischemic and hemorrhagic strokes in young adults; e. g. -congenital heart disease (patent foramen ovale), valvular heart disease, family history of stroke, premature atherosclerosis, connective tissue disease with vasculitis, hematological variables, smoking, drug abuse, some genetic disease, coagulopathy, arteriovenous malformation (AVM), aneurysm, and in female oral contraceptive pill, pregnancy, postpartum state, migraine etc. This suggest that it should be possible to make a considerable impact on the stroke incidence in young adults by minimizing the relevant risk factors in the population by screening or case finding for high risk individuals to whom preventive treatment may be offered.

In terms of risk factors stroke in young adults is remarkably heterogeneous and often a diagnostic challenge. Western reports show that in this age group, cardio embolization and non atherosclerotic vasculopathies are relatively important risk factors of ischemic stroke as compared to atherosclerotic vasculopathy and small artery occlusion which is common in elderly. It is important to find out the etiologic factors and management of these factors adequately for appropriate prevention and recurrence. Type of stroke in young adults may influence the outcome and may have a dramatic impact in the quality of life in survivors ${ }^{5}$. Regarding hemorrhagic stroke in young adults subarachnoid hemorrhage and intracerebral hemorrhage are common in this group than older $^{6-8}$ This study was designed to find out the risk factors of stroke in young adults in Dhaka Medical College Hospital.

\section{Materials and Methods:}

This cross-sectional study was conducted in the Department of Medicine and Department of Neurology, Dhaka Medical College, Dhaka, during the period of April to October 2016. We studied consecutive 100 stroke patients between the age of 15 and 45 . Detailed history was taken and all patients were examined thoroughly to elicit the aetiological and risk factors. All were investigated with routine blood count, urine examination, blood glucose, lpid profile, serum creatinine, ECG, chest X-ray and CT scan of brain. Further investigations were done according to the clinical and laboratory findings.

\section{Results:}

The maximum number of patients $(29 \%)$ in this study were in between 40-45 years followed by (24\%) between the age of $35-39$ years. Sixty two percent were male and $38 \%$ were female. In this series only $13 \%$ was illiterate. Of the literate group
$30 \%$ went to primary school and $16 \%$ completed graduations. Fifty five percent patients came from urban areas and majority patients comprised of house wife (24\%) followed by service holder (20\%) and unemployed (19\%). 38\% were smoker whereas $8 \%$ had the habit of betel nut chewing (Table I). $65 \%$ suffered from ischemic stroke, $25 \%$ suffered from intracerebral hemorrhage, $10 \%$ suffered from subarachnoid hemorrhage (Figure 1). About sixty eight percent patients with infarctive stroke had high level of LDL (Table II) and $62.22 \%$ patients with haemorrhagic stroke had high lipid level (Table III).

Table I: Distribution by Socio-demographic variable $(n=100)$

\begin{tabular}{lcc}
\hline Patient characteristics & $\begin{array}{c}\text { Numbers of } \\
\text { the patients }\end{array}$ & $\begin{array}{c}\text { Percentage } \\
(\%)\end{array}$ \\
\hline
\end{tabular}

Age groups (in years):

- 15-19

08

08

- 20-24

10

10

- 25-29

19

19

- 30-34

10

10

- $\quad 35-39$

24

24

- 40-45

29

29

Sex:

- Male

62

62

- Female

38

38

Literacy:

- Illiterate

13

13

- Primary

30

30

- Secondary

41

- Higher Secondary

41

16

16

Residence:

- Urban

- Rural

55

55

Occupation:

- $\quad$ Service

20

20

- Business

09

09

- Student

12

12

- Laborer

10

10

- Cultivator

06

06

- House wife

24

24

- Unemployed

19

19

Habit:

- $\quad$ Smoking

38

38

- Betel nut

08
08 


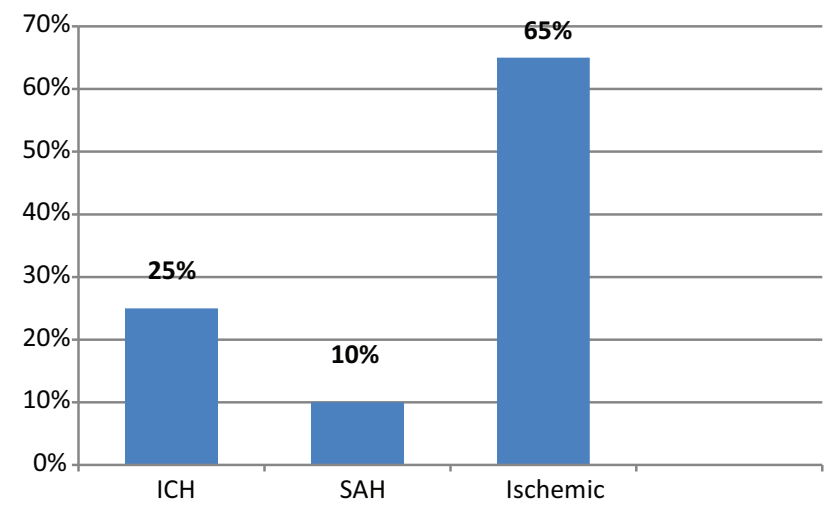

Figure 1: Types of Stroke

Among the hypertensive patients only $25 \%$ were compliant to antihypertensive medications. A good number of patients (35\%) were diagnosed as hypertensive for the first time after admission in hospital (Table IV). Out of 12 diabetic patients,
$50 \%$ were previously diagnosed. Among them $33.33 \%$ had controlled and the remaining $16.66 \%$ had uncontrolled diabetes mellitus (Table V).

$16 \%$ of the stroke suffered female patients used oral contraceptive in their life time, $84 \%$ never used oral contraceptive during the acute attack. In this series only $2 \%$ of the patients were suffering from SLE, another $2 \%$ were due to vasculitis (Takayasu arteritis). Dyslipidemia was associated with $76.91 \%$ infarctive stroke patients (Table VI) and $62.22 \%$ patients of haemorrhagic stroke (Table VII).

Among 10 patients of subarachnoid hemorrhage 8 (80\%) had ruptured aneurysm and 2 (20\%) had ruptured AVM. Majority (75\%) of aneurysmal subarachnoid hemorrhage were due to ruptured anterior communicating artery aneurysm followed by $12.5 \%$ posterior communicating artery and $12.5 \%$ middle cerebral artery.

Table II:Lipid profile of patient with infarctive stroke $(n=65)$

\begin{tabular}{lccc}
\hline Abnormal lipid profile & Male & Female & Total \\
\hline High LDL $(\geq 100 \mathrm{mg} / \mathrm{dl})$ & $36(55.38 \%)$ & $8(12.30 \%)$ & $44(67.68 \%)$ \\
Low HDL $(<35 \mathrm{mg} / \mathrm{dl})$ & $28(43.07 \%)$ & $8(12.30 \%)$ & $36(55.37 \%)$ \\
High Cholesterol $(>200 \mathrm{mg} / \mathrm{dl})$ & $16(24.61 \%)$ & $4(6.15 \%)$ & $20(30.76 \%)$ \\
Triglyceride $(>150 \mathrm{mg} / \mathrm{dl})$ & $8(12.30 \%)$ & $8(12.30 \%)$ & $16(24.60 \%)$ \\
\hline
\end{tabular}

Table III: Lipid profile of patient with haemorrhagic stroke $(n=35)$.

\begin{tabular}{lccc}
\hline Abnormal lipid profile & Male & Female & Total \\
\hline High LDL $(\geq 100 \mathrm{mg} / \mathrm{dl})$ & $14(40.00 \%)$ & $10(22.22 \%)$ & $24(62.22 \%)$ \\
Low HDL $(<35 \mathrm{mg} / \mathrm{dl})$ & $14(40.00 \%)$ & $6(17.14 \%)$ & $20(57.14 \%)$ \\
Triglyceride $(>150 \mathrm{mg} / \mathrm{dl})$ & $16(45.71 \%)$ & $0(\%)$ & $16(45.71 \%)$ \\
Cholesterol $(>200 \mathrm{mg} / \mathrm{dl})$ & $4(11.42 \%)$ & $0(\%)$ & $4(11.42 \%)$ \\
\hline
\end{tabular}

Table IV: Stroke with hpertension $(n=40)$

\begin{tabular}{lcc}
\hline Hypertension & Number of patients & Percentage (\%) \\
\hline Previously known & 26 & 65 \\
- Compliant & 10 & 25 \\
- $\quad$ Non-compliant & 16 & 40 \\
Diagnosed on admission & 14 & 35 \\
\hline Total & 40 & 100 \\
\hline
\end{tabular}

Table V: Stroke with Diabetes Mellitus $(n=12)$

\begin{tabular}{lcc}
\hline Diabetes Mellitus & Number of patients & Percentage (\%) \\
\hline Previously known & 06 & 50 \\
- $\quad$ Controlled & 04 & 33.33 \\
- $\quad$ Uncontrolled & 02 & 16.66 \\
Diagnosed on admission & 06 & 50 \\
\hline Total & 12 & 100 \\
\hline
\end{tabular}


Table VI: Different risk factors of infarctive stroke with male, female distribution $(n=65)$.

\begin{tabular}{lccc}
\hline Risk factors & Male & Female & Total \\
\hline Dyslipidemia & $28(43.07 \%)$ & $22(33.84 \%)$ & $50(76.91 \%)$ \\
Mitral stenosis & $8(12.30 \%)$ & $15(23.07 \%)$ & $23(35.37 \%)$ \\
Hypertension & $10(15.38 \%)$ & $10(15.38 \%)$ & $20(30.76 \%)$ \\
Smoking & $16(24.61 \%)$ & $2(3.07 \%)$ & $18(27.68 \%)$ \\
OCP & & $18(63.16 \%)$ & \\
DM & $4(6.15 \%)$ & $0(0 \%)$ & $4(6.15 \%)$ \\
IHD & $2(3.07 \%)$ & $2(3.07 \%)$ & $4(6.14 \%)$ \\
\hline
\end{tabular}

Table VII: Different risk factors of haemorrhagic stroke with male, female distribution $(n=35)$.

\begin{tabular}{lccc}
\hline Risk factors & Male & Female & Total \\
\hline Dyslipidemia & $14(40.00 \%)$ & $10(22.22 \%)$ & $24(62.22 \%)$ \\
Hypertension & $12(34.28 \%)$ & $8(22.85 \%)$ & $20(57.13 \%)$ \\
Smoking & $18(51.42 \%)$ & $2(5.71 \%)$ & $20(57.13 \%)$ \\
OCP & & $6(25.00 \%)$ & \\
DM & $6(17.14 \%)$ & $2(5.71 \%)$ & $8(22.85 \%)$ \\
IHD & $2(5.71 \%)$ & $0(0 \%)$ & $2(5.71 \%)$ \\
\hline
\end{tabular}

\section{Discussion:}

Stroke incidence rises exponentially with increasing age. In this study, all the patients were grouped in six age groups. Majority of the study subjects were above 40 years of age. A hospital based study done in Dhaka Medical College Hospital showed that only $1 \%$ stroke occurred in $<20$ years and $26 \%$ in 20-45 years. There is not enough study of stroke in young adults (15-45 years) in Bangladesh.

In this study, $62 \%$ patients were male and $38 \%$ were female, male incidence is $24 \%$ higher than female and ratio is 1.38 . Gender variation was not very much significant with slight male predominance and consistent with other studies. ${ }^{9}$

Though it is observed in many studies that haemorrhages are the more common than infarction in young age, in our study CT and MRI findings of the studied patients show that $65 \%$ had ischemic stroke while $35 \%$ had hemorrhage . Higher rate of hemorrhagic stroke is also have been reported in a number of hospital series in Asian countries such as Singapore, Malaysia (33\%), Thailand (30\%), Korea (31\%), Taiwan (31\%). Higher rate of hemorrhage stroke in this present hospital based study may be due to the fact that acute admission is more related to the hemorrhagic stroke. Among the associated risk factors in infarctive stroke cases, dyslipidemia is present in $76.91 \%$ cases. Other mostly associated risk factors are mitral stenosis, hypertension, smoking, OCP, In haemorrhagic cases, dyslipidemia is again found to be the highest associated risk factor present in 85 . $71 \%$ cases. Other frequent factors are hypertension, smoking.

In this study cardiogenic cerebral embolus is one of the most common cause of ischemic stroke in the young, accounting for up to $35.37 \%$ of cases. Among the cardio embolic causes the mitral valvular disease is the most common. Most of the patient with valvular heart disease had history of Rheumatic Fever. Valvular heart diseases were more prevalent in the female group in this study. Bevan et al showed that about $35.4 \%$ cerebral infracts are due to cardio embolic source. However, in some studies, it was found that cardioembolic disease as cause of infarction is less common in developing countries in contrast to atherothrombotic disease which is more common. ${ }^{16-17}$

Present study shows that $40 \%$ of the stroke patients are suffering from HTN. Study among the NIDDM within BIRDEM by Latif et al found $50.3 \%$ of the patient were hypertensive. Bevan et al showed that $31 \%$ of the patient with cerebral infarction had HTN. The present study correlates with this western study. This study shows that $35 \%$ stroke patients were hypertensive and $40 \%$ were on irregular treatment. This present study is almost similar with the study of Chowdhury et al, who studied 74 hypertensive patients with suffered stroke and had shown that $34 \%$ of the patients were not aware that they were hypertensive and 60 . $7 \%$ were on irregular treatment. Yoshinaryi et al showed in his study that the percentage of ischemic stroke was similar with normotensive patients but the incidence was higher in untreated cases of HTN. Hypertension is more frequent in haemorrhagic strokes than Infarctive cases So, effective control of HTN is essential.

Diabetes mellitus was not commonly associated risk factor found in our study like other studies. ${ }^{9}$ Dyslipidemia remains as a silent risk factor regarding both Infarctive and haemorrhagic stroke. In our study we have found that associated lipid abnormality is high LDL in both Infarctive and haemorrhagic strokes present in $67.68 \%$ and $62.22 \%$ cases respectively. Low HDL is also common in both types 55. $37 \%$ and 57. 14\% cases respectively. High cholesterol level is found to be more associated with infarction than haemorrhage.

Hayee et al showed that $19.07 \%$ of the total cases of stroke had raised serum cholesterol which is lower than the present study. The role of dyslipoproteinaemia in the pathogenesis of cerebrovascular disease in less certain than for coronary artery disease; more consistent association has been noted with low HDL cholesterol and high total cholesterol to HDL cholesterol ratio than with total cholesterol, low density lipoprotein cholesterol and triglycerides. ${ }^{12} \mathrm{HDL}$ cholesterol 
plays a fundamental role in the regulation of atherogenesis via its effects on reverse cholesterol transport ${ }^{13}$ and vascular remodeling. ${ }^{14}$ However as dyslipidemia is highly prevalent as associated risk factor, it is likely that premature atherosclerosis may consist a considerable proportion of aetiology of young stroke.

The present study shows that 38\% patients were smoker. Multiple individual studies have demonstrated that the risk of stroke is increased among the cigarette smokers.

There is little doubt that regular use of estrogen is associated with increased risk of stroke. In this study out of 38 female patients, $63.16 \%$ patient had history of taking OCP, $36.84 \%$ of patient never used oral contraceptives in their life time. The use of OCP is associated with nine fold increase risk of cerebral infraction in women. Physical activity has inverse relationship with the stroke. Exercise is effective in the prevention of cardiovascular disease and stroke. The benefits are largely manifested through the role that exercise plays an important role in control of certain modifiable risk factors such as blood lipid abnormalities, diabetes and obesity. This study shows that during onset of stroke $72 \%$ were during rest, $24 \%$ at work. This study indicates that, those who were hard workers were affected less. Herman et al suggested that physical activity reduces the risk of stroke. Hart et al ${ }^{15}$ studied 416 men who had stroke and revealed that men with manual occupation and men whose father had manual occupation had significantly higher rate of stroke than men in non manual worker. In this present study sedentary workers form the major percentage of stroke.

\section{Conclusion:}

In this study a number of modifiable risk factor were identified, of which dyslipidemia, valvular heart disease and HTN are important risk factor, next are smoking, DM and IHD. Stroke is more preventable than to cure. In an underdeveloped country like ours, the best policy for combating stroke is primary prevention. Most of the valvular heart diseases are rheumatic in origin, which can be prevented through primary and secondary prevention of rheumatic fever. By controlling HTN we significantly reduce the incidence of stroke. Smoking, one of the frequent risk factor for stroke, can be controlled by anti-smoking campaign. Proper screening, counseling, regarding diet and ensuring drug compliance can control IHD and DM which are the other important risk factors. Preventive measures focus on the risk factors and etiology should be strongly enforced in young adults and aggressive treatment and secondary prevention as well as rehabilitation should be considered.

\section{Conflict of interest: None.}

\section{References:}

1. Ropper A H, Brown R H. Adam's and Victor's Principles of neurology. New York: McGraw hill; 2005:708-710.
2. Ji R, Schwamm LH, Pervez MA, Singhal AB. Ischemic stroke and transient ischemic attack in young adults: risk factors, diagnostic yield, neuroimaging, and thrombolysis. JAMA Neurol 2013;70(1):51-7.

3. Mohammad Q D, Alam B, Habib M, Hossain S, Haque B, Haque A, et al . Prevalence of stroke in Bangladeshi population-A population based study. JAFMC 2009;5(1):24-7.

4. Lipska K, Sylaja P N, Sarma P S, Thanka K R, Kutty V R. Risk factors for acute ischemic stroke in young adults in South India. JNNP 2007; 78:959- 63.

5. H. Marini C, Totaro R, De Santis F, Morris T, Barnett S, Bacoulas $\mathrm{M}$, et al. Stroke in young adults in the community in Italy. Stroke 2001;32 (1):180- 210.

6. Marini C, Totaro R, De Santis F, Ciancarelli I, Baldassarre M, Carolei A. Stroke in young adults in the communitybased L' Aquila registry: incidence and prognosis. Stroke 2001:32; (1)52-6.

7. Jacobs BS, Boden-Albala B, Lin IL, Sacco RL, Stroke in the young in the Northern Manhattan stroke study. Stroke 2002:33 (12):2789-983.

8. Gandolfo C, Conti M. Stroke in young adults: Epidemiology Neurological Sciences 2003;24: S1-3.

9. Nedeltchev K, der Maur TA, Georgiadis D, Arnold M, Caso $\mathrm{V}$, Mattle HP et al. Ischaemic strokes in young adults: predictors of outcome and recurrence. J Neurol Neurosurg Psychiatry 2005; 76: 191-5.

10. Putaala J, Metso AJ, Metso TM, Konkola N, Kraemer Y, Haapaniemi E et al. Analysis of 1008 consecutive patients aged 15-49 with first ever ischemic stroke, the Helsinki young stroke registry. Stroke 2009; 40 (4): 1195-1203.

11. Varona JF, Guerra JM, Bermejo F, Molina JA, Gomez de la Cámara A. Causes of ischemic Stroke in young adults and evolution of the etiological diagnosis over the Long term. European Neurology 2007; 57 (4):212-18.

12. Curb JD, Abbott RD, Rodriguez BL, Masaki KH, Chen R, Popper JS. High density lipoprotein cholesterol and the risk of stroke in elderly men:the Honolulu Heart Program. Am J Epidemiol 2004;160:150-7.

13. Lewis GF, Rader DJ. New insights into the regulation of HDL metabolism and reverse cholesterol transport. Circ Res 2005;96:1221-32.

14. Alagona C, Soro A, Westerbacka J, Ylitalo K, Salonen JT, Salonen $\mathrm{R}$ et al. Low HDL cholesterol concentration is associated with increased imtima-media thickness independent of arterial stiffness in healthy subjects from families with low HDL cholesterol. Eur J Clin Invest 2003;33:457-63.

15. Hart CL, Hole DJ, Smith GD. Influence of socioeconomic circumstance in early and later life on stroke risk among men in a Scottish cohort study. Stroke 2000; 31 (9): 2093-7.

16. Lee T-S, Hsu W-C Chen C-J, et al. Etiologic study of young ischemic stroke in Taiwan. Stroke 2002;33: 1950-5.

17. Garbusinski JM, van der Sande MA, Bartholome EJ, Dramaix M, Gaye A, Coleman R et al. Stroke presentation and outcome in developing countries. Stroke 2005; 36: 1388-93. 